\title{
Legislación de los recursos naturales aplicables a cambio climático
}

\section{Legislation of natural resources applicable to climate change}

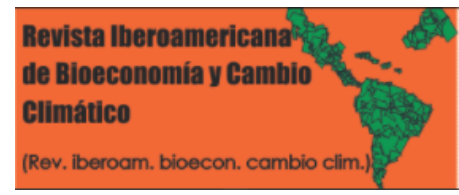

\author{
Santivañez, José Luis; Baqueros Ballón, Fátima; Martínez Dávila, Juan \\ Pablo; Cruz Centeno, José Fredy; Toruño, Pedro José; Editor Dr. Angel \\ Sol Sanchez
}

\author{
José Luis Santivañez \\ jsantiva@catie.ac.cr \\ Estado Plurinacional de Bolivia, Bolivia \\ Fátima Baqueros Ballón \\ jsantiva@catie.ac.cr \\ Campus Veracruz, Mexico \\ Juan Pablo Martínez Dávila \\ jsantiva@catie.ac.cr \\ Facultad Multidisciplinaria Paracentral Universidad de \\ El Salvador, El Salvador \\ José Fredy Cruz Centeno \\ jsantiva@catie.ac.cr \\ Agroecología. UNAN-León., Nicaragua \\ Pedro José Toruño \\ jsantiva@catie.ac.cr \\ Agroecología. UNAN-León., Nicaragua \\ Editor Dr. Angel Sol Sanchez \\ Colegio de postgraduados, Mexico, México
}

\section{Revista Iberoamericana de Bioeconomía y Cambio Climático \\ Universidad Nacional Autónoma de Nicaragua, León, Nicaragua ISSN-e: 2410-7980 \\ Periodicidad: Semestral \\ vol. 2, núm. 1, 2016 \\ czuniga@ct.unanleon.edu.ni}

Recepción: 15 Mayo 2015

Aprobación: 31 Enero 2016

URL: http://portal.amelica.org/ameli/journal/394/3941750011,

DOI: https://doi.org/10.5377/ribcc.v2i1.5685

Autor de correspondencia: jsantiva@catie.ac.cr
Resumen: El medio Ambiente, los Recursos Naturales y la Biodiversidad, están considerada entre las prioridades para implementar procesos de gestión de largo plazo en todos los países del mundo, empleadas y usadas como banderas de reivindicación social, económica, cultural, económica y política. Sin embargo las unidades o ministerios gozan del más bajo presupuesto, no están en las primeras filas de priorización de los POA, hay tardías reacción y escasos profesionales capacitados, especializados y contratados. Bolivia tiene cuantiosas normas con distintos nombres y un solo énfasis: "Mecanismos de Regulación”, lo que involucra sistemas de prevención bajo un principio precautorio, donde podemos viabilizar, con imaginación y voluntad, acciones inmediatas. A partir de la Década de los 70 en nuestro país se va promulgando algunos instrumentos legales relativos a la gestión ambiental: a) en 1975 donde se considera la Vida Silvestres, los Parques Nacionales y la Caza y Pesca para dar comienzo a un proceso interesante en la gestión de los Recursos Naturales (la Ley de la Vida Silvestre, Parques Nacionales, Caza y Pesca: DL 12301, 14/03/1975); b) en 1980 se traza una línea para incorporar en la actividad minera algunos resguardos, los que no dieron muchos resultados por su falta de consenso con los actores; c) entre el 1985 1989, para promover el sector productivo nacional se desarrollan algunas agendas que precautele el tema del agua, pero otra vez tendientes a regular el sector minero y el uso de tan vital recurso; d) entre el 91-92, dado los compromisos asumidos por el país en las reuniones preparatorias para la cumbre sobre Medio Ambiente y Desarrollo de Rio de Janeiro, se incluye en la agenda política las preocupaciones de orden ambiental, iniciándose de esta manera un debate serio sobre el paradigma referido al desarrollo y la conservación, dando pie la formulación de la Ley de Medio Ambiente (DS 1333, 27/04/1992); e) en 1996, después de un amplio proceso de investigación, se formula la Ley Forestal (DS 1700, 12/07/1996), dada la vocación forestal del país con más de $52 \mathrm{MM} /$ ha de bosques, donde el contexto ambiental, la conservación, las funciones ecosistemas y sus atributos de alto valor son importantes; f) a partir de 1999 Bolivia afronta la conservación de la biodiversidad y los Recursos naturales desde una mirada técnica con el Programa Nacional de Cambios Climáticos, que culmina su accionar el 2014 con base a las nuevas políticas del país, donde el tema climático y la gestión de los recursos naturales es un tema de política exterior; g) el 2010 Bolivia convoca y es sede de la 
Conferencia Mundial de los Pueblos sobre Cambio Climático y Derechos de la Madre Tierra (Tiquipaya 2010) logrando reunir más de 30.000 representantes de gobiernos, Organizaciones Sociales, Naciones y Pueblos del Mundo; h) para el 2012 se promulga la Ley de la Madre Tierra (DS: 300) y con ella el órgano rector de las políticas del vivir bien con soberanía, con un órgano rector como es la Autoridad Plurinacional de la Madres Tierra y políticas que contrarrestan la mercantilización de los recursos naturales a través del: Mecanismo Conjunto de Mitigación y Adaptación para el Manejo Integral y Sustentable de los Bosques y la Madre Tierra. El medio Ambiente, los Recursos Naturales y la Biodiversidad, están considerada entre las prioridades para implementar procesos de gestión de largo plazo en todos los países del mundo, empleadas y usadas como banderas de reivindicación social, económica, cultural, económica y política. Sin embargo las unidades o ministerios gozan del más bajo presupuesto, no están en las primeras filas de priorización de los POA, hay tardías reacción y escasos profesionales capacitados, especializados y contratados. Bolivia tiene cuantiosas normas con distintos nombres y un solo énfasis: "Mecanismos de Regulación”, lo que involucra sistemas de prevención bajo un principio precautorio, donde podemos viabilizar, con imaginación y voluntad, acciones inmediatas. A partir de la Década de los 70 en nuestro país se va promulgando algunos instrumentos legales relativos a la gestión ambiental: a) en 1975 donde se considera la Vida Silvestres, los Parques Nacionales y la Caza y Pesca para dar comienzo a un proceso interesante en la gestión de los Recursos Naturales (la Ley de la Vida Silvestre, Parques Nacionales, Caza y Pesca: DL 12301, 14/03/1975); b) en 1980 se traza una línea para incorporar en la actividad minera algunos resguardos, los que no dieron muchos resultados por su falta de consenso con los actores; c) entre el 1985 - 1989, para promover el sector productivo nacional se desarrollan algunas agendas que precautele el tema del agua, pero otra vez tendientes a regular el sector minero y el uso de tan vital recurso; d) entre el 91-92, dado los compromisos asumidos por el país en las reuniones preparatorias para la cumbre sobre Medio Ambiente y Desarrollo de Rio de Janeiro, se incluye en la agenda política las preocupaciones de orden ambiental, iniciándose de esta manera un debate serio sobre el paradigma referido al desarrollo y la conservación, dando pie la formulación de la Ley de Medio Ambiente (DS 1333, 27/04/1992); e) en 1996, después de un amplio proceso de investigación, se formula la Ley Forestal (DS 1700, 12/07/1996), dada la vocación forestal del país con más de $52 \mathrm{MM} / \mathrm{ha}$ de bosques, donde el contexto ambiental, la conservación, las funciones ecosistemas y sus atributos de alto valor son importantes; f) a partir de 1999 Bolivia afronta la conservación de la biodiversidad y los Recursos naturales desde una mirada técnica con el Programa Nacional de Cambios Climáticos, que culmina su accionar el 2014 con base a las nuevas políticas del país, donde el tema climático y la gestión de los recursos naturales es un tema de política exterior; g) el 2010 Bolivia convoca y es sede de la Conferencia Mundial de los Pueblos sobre Cambio Climático y Derechos de la Madre Tierra (Tiquipaya 2010) logrando reunir más de 30.000 representantes de gobiernos, Organizaciones Sociales, Naciones y Pueblos del Mundo; h) para el 2012 se promulga la 
Ley de la Madre Tierra (DS: 300) y con ella el órgano rector de las políticas del vivir bien con soberanía, con un órgano rector como es la Autoridad Plurinacional de la Madres Tierra y políticas que contrarrestan la mercantilización de los recursos naturales a través del: Mecanismo Conjunto de Mitigación y Adaptación para el Manejo Integral y Sustentable de los Bosques y la Madre Tierra.

Palabras clave: Madre Tierra, Mecanismos Conjunto, Gestión Integral, Sujeto, Mitigación y Adaptación, Madre Tierra, Mecanismos Conjunto, Gestión Integral, Sujeto, Mitigación y Adaptación.

Abstract: Environment, Natural Resources and Biodiversity, are considered among the priorities for implementing management processes long term all countries, employed and used as flags of social, economic, cultural, economic and political demands. However units or ministries enjoy the lowest budget, they are not in the forefront of prioritizing the POA, no late reaction and few trained and hired specialized professionals. Bolivia has substantial rules with different names and a single focus: "Mechanisms of Regulation", which involves prevention systems under a precautionary principle, which can make possible, with imagination and will, immediate action. From the decade of the 70 in our country it will enact some legal instruments on environmental management: a) in 1975 which is considered the Wild Life, National Parks and Game and Fish to start an interesting process Management of Natural Resources (Law of Wildlife, National Parks, Fishing and Hunting: DL 12301, 14.03.1975); b) in 1980, a line is drawn to incorporate some safeguards mining activity, which did not give many results for its lack of consensus with the actors; c) between 1985 1989 , to promote national productive sector precautele some agendas that water issues are developed, but again aimed at regulating the mining sector and the use of such a vital resource; d) between 91-92, since the commitments made by the country in the preparatory meetings for the Summit on Environment and Development in Rio de Janeiro, is included on the agenda concerns environmental, thereby initiating a debate serious about the paradigm based on the development and conservation, giving rise formulating the Environmental Law (DS 1333, 27.4.1992); e) in 1996, after extensive research process, the Forest Law (DS 1700, 12/07/1996) is formulated in view of the forest land in the country with over $52 \mathrm{MM} /$ ha of forests where the environmental context, conservation, ecosystem functions and high value attributes are important; f) from 1999 Bolivia faces the conservation of biodiversity and natural resources from a technical look with the National Climate Change Programme, which ends its action in 2014 based on the new policies of the country where the climate issue and the management of natural resources is a matter of foreign policy; g) 2010 Bolivia convenes and hosts the World People's Conference on Climate Change and the Rights of Mother Earth (Tiquipaya 2010) managing to reunite more than 30,000 representatives of governments, social organizations, nations and peoples; h) for the 2012 Law of Mother Earth (DS is passed, 300) and with it the guiding policy of living well with sovereignty, with a governing body such as the 


\begin{abstract}
Plurinational Authority Mother Earth and political body that counteract the commodification of natural resources through: Joint Mechanism for Mitigation and Adaptation for Integral and Sustainable Management of Forests and Mother Earth.
\end{abstract}

Keywords: Mother Earth mechanisms set, Comprehensive Management, Subject, Mitigation and Adaptation.

\title{
1. INTRODUCCIÓN
}

Para poner en contexto los procesos que conllevan hablar de legislaciones desarrolladas sobre cambio climático, vale tomar nota un fragmento dado por el Secretario General de las Naciones Unidas, Ban Kimoon en la: "Conferencia Mundial de los Pueblos Sobre Cambio Climático y Defensa de la Madre Tierra, en Tiquipaya - Bolivia el 2010": Hay la necesidad de establecer un mejor diálogo y una mayor participación de todos en la búsqueda de soluciones para luchar contra el cambio climático". "El cambio climático es un tema ético que tiene serias repercusiones en el bienestar de nuestra generación y de las generaciones venideras, porque este problema requiere de una solución global que tome en cuenta las opiniones y necesidades de todos los que compartimos la Madre Tierra" (UN-NGLS 2010)

Para concretar las demandas globales ha sido necesario un proceso de concertación, alentador en algunos casos y desalentador en otros, fomentado por una emergente problemática de resultados negativos impensables por la población común pero ya expuesta en más de 2 siglos por algunos pensadores. Esta problemática denominada Cambio Climático, que está generando incertidumbres de un futuro alentador está generando resultados y consecuencias calamitosas sobre los pueblos del mundo, sus medios de vida, los recursos naturales, la biodiversidad, la inseguridad alimentaria, los déficit palpable de acceso a agua de calidad y en cantidad y una magra economía que va carcomiendo y corroyendo los principios básicos de las Culturas, Naciones, Gobiernos y gobernantes.

El tema de cambio climático, las preocupaciones por las consecuencia y las acciones de mitigación y adaptación, se han convertido en un Eslogan de la Política Internacional, Discurso en la Política Local y un Tema de Moda en la Gestión de Fondos para las Instituciones. En temas presupuestarios, recursos humanos y desarrollo de políticas públicas, los países invierten muy pocos recursos para fomentar la Ciencia y la Tecnología, Acciones Estratégicas y Medidas a Implementar en Adaptación y Mitigación ante el Cambio Climático. Se estima que el cambio climático puede generar daños económicos sin medidas oportunas y pertinentes: a) > 5\% del PIB global; b) 1\% del PIB global la estabilización de las emisiones entre 500 y $550 \mathrm{ppm}$ CO2; c) 37 billones de dólares el desarrollo de medidas de Adaptación, d) > 70\% de la población de la Región Andina tendrán problemas de acceso a agua para el consumo al 2025; e) > de 40 millones de personas estarían en riesgo por falta de agua al 2020; f) la Región Andina podría perder $>4.5 \%$ de su PIB con problemas de deterioro de su económica (GIZ 2011).

\section{CONSTRUCCIÓN DEL PROCESO}

\subsection{Las negociaciones sobre el Cambio Climático}

Notas DE AUTOR 
La preocupación creciente ha generado reacciones, siendo las Naciones Unidas ha jugado un papel muy importante en los procesos de negociación que se han desarrollado desde los años 80s, con unas 24 reuniones, en tres etapas3:

- Etapa 1. 1988-1994: Conocida como el etapa Convención, con la creación del entorno institucional, empezando con el Panel Intergubernamental sobre Cambio Climático (IPCC), y la Convención Marco de las Naciones Unidas sobre Cambio Climático (CMCC).

- Etapa 2: 1995-2008: Denominada como Promesas y Evaluaciones. Es dan inicios a las COP, con procesos de negociación, presentación por parte de los países de las medidas de reducción de emisiones; creación del Protocolo de Kyoto;

- Etapa 3: 2009-2015: También Llamada Arquitectura de los Acuerdo, que se da inicio con la COP 15 la cual concluye con la COP 21 desarrollada en París.

Este proceso nos permite ver cuatro importantes periodo: a) la Cumbre de la Tierra de Rio de Janeiro, Brasil (1992), cuando se establece la Convención Marco de las Naciones Unidas sobre Cambio Climático (CMCC); b) acuerdo del protocolo de Kyoto, Japón (1997); c) los acuerdo de Marrakech, Marruecos, que debilitan el protocolo de Kyoto (2001); d) la plataforma de Durban, Sudáfrica, para la acción ampliada (2011); d) acuerdos consensuados en la COP 21, Francia (Tabla 1).

TABLA Nº 1

El proceso de concertación y socialización para afrontar una agenda climática internacional

\begin{tabular}{|c|c|c|c|}
\hline Nominación & Contexto & Pais & Año \\
\hline $\begin{array}{l}\text { Conferencia de UN sobre UA } \\
\text { Humano }\end{array}$ & Se debahe el tema de la degradacion medioambiental Humana. & $\begin{array}{l}\text { Estocolma. } \\
\text { Soecia }\end{array}$ & 1072 \\
\hline Creación del IPCC & $\begin{array}{l}\text { Programa de las Naciones Unidas para el Medio Ambiente (PNUMA) y la Ocpanieación } \\
\text { Meteorolibica Mundial (MMO) }\end{array}$ & $\begin{array}{l}\text { Buenos Aires. } \\
\text { Acpentina }\end{array}$ & 1038 \\
\hline Primer Reporte del IPCC & Se lams a unir esherzos en is cooperación internacional para estabilear las csncentraciones & & 1980 \\
\hline La Cumbre de la Tiers & 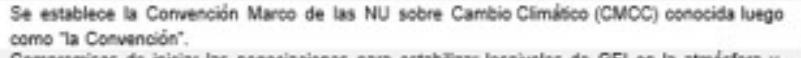 & $\begin{array}{l}\text { Ris se } \\
\text { Janeiro, Brasil }\end{array}$ & 10602 \\
\hline $\begin{array}{l}\text { Comienzan las fumeiones de la } \\
\text { Convención: }\end{array}$ & 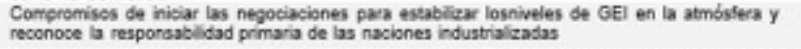 & & 1004 \\
\hline Reunibin de las Parses COP 1 & El "Mandass de Berin' establece una fase ploto hasto el aho 2050. S4gundo Repone del IPCC. & $\begin{array}{l}\text { Berlin } \\
\text { Alemania }\end{array}$ & $10 \% 5$ \\
\hline Reunión de las Partes COP 2 & $\begin{array}{l}\text { Endorsan al IPCC2 y a les acuendos de la COP1. La OPEP deja de oponerse a las acciones de la } \\
\text { Convención }\end{array}$ & Ginebra. & 1096 \\
\hline Reunibon de laspartes COP 3 & 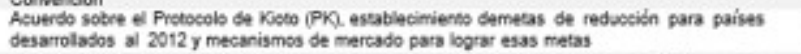 & Kyous. Japben & 1997 \\
\hline Reunión de las Partes COP 4 & $\begin{array}{l}\text { Acuerdos de un Plan de Acoido para el seguimiants del PK incluyendo les estimulos para la } \\
\text { transferencia becnologica. Sinacverdos en los mecanismos de Kioto }\end{array}$ & $\begin{array}{l}\text { Buenos Aires. } \\
\text { Avgentina }\end{array}$ & $10 \% 6$ \\
\hline Reunibn de las Partes COP 5 & No tay avanses en los acuerdos sobre los mecarismos de Koto a aplicarse & $\begin{array}{l}\text { Benn. } \\
\text { Alemania }\end{array}$ & $10 \% 0$ \\
\hline Reunibn de las Parses COP 6 & $\begin{array}{l}\text { Terow repone del IPCC. Fracasan las negociaciones sobre les mecaniamos de Kioto. La weunión } \\
\text { es suspendida. }\end{array}$ & $\begin{array}{l}\text { La Haya. } \\
\text { Holanda }\end{array}$ & 2000 \\
\hline Reunich de las Parces COP 7 & Acuerdo de Marrakech. Se conerean las acuerdes para poner en marcha el PK & $\begin{array}{l}\text { Marrakech. } \\
\text { Marrueces }\end{array}$ & 2001 \\
\hline Reumibin de las Parves COP 8 & Las negosiaciones continúan sin lograse la ractcación de PKY sin progreso widena & $\begin{array}{l}\text { Nueva Delhi, } \\
\text { India }\end{array}$ & 2002 \\
\hline Revinibn de laspartes COP 9 & 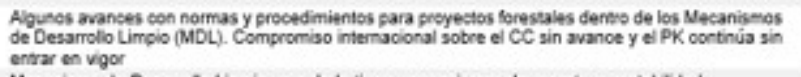 & Milin, italig & 2000 \\
\hline Reunión de las Partes COP 10 & Mecanismo de Desarrollo Limplo, uso de la tierra, mecanismos de reporte y contablidad. & $\begin{array}{l}\text { Buenos Aires, } \\
\text { Acgentina }\end{array}$ & 2004 \\
\hline Reunión de las Partes COP 11 & $\begin{array}{l}\text { 1a. Reunión de las Partes del Protooolo de Koto (MOP 1), avanoes en la implementación de } \\
\text { los mecanismos del PK. }\end{array}$ & $\begin{array}{l}\text { Montreal. } \\
\text { Canada }\end{array}$ & 2005 \\
\hline Reunibin de lasparnes COP 12 & 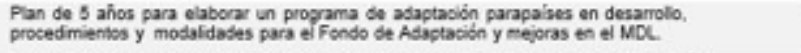 & Nairobikanya & 2006 \\
\hline Reunibn de laspartes COP 13 & $\begin{array}{l}\text { Se crea dos mecanismos paraleles (Uno dentro del PK (AWG-KP) y otro para la acción } \\
\text { cooperativa. Cuarto Reporte del IPCC. }\end{array}$ & $\begin{array}{l}\text { Bali. } \\
\text { Insonesis }\end{array}$ & 2007 \\
\hline Reunicin de las Partes COP 14 & Con poces avances de la COP anterior. Acciones en los mecanismos de astaptación & $\begin{array}{l}\text { Poseran, } \\
\text { Polonia }\end{array}$ & 2008 \\
\hline Reunión de las Partes COP 15 & Un borrador de Deciarzoión proparaso a prori por dingentes de paises industrialzados, pero sin & Copenhague. & 2000 \\
\hline Reunión de laspentes COP if & 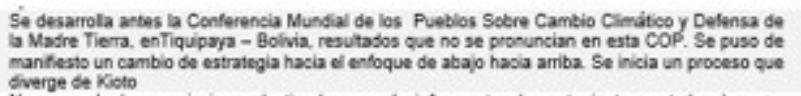 & $\begin{array}{l}\text { Cancoin. } \\
\text { Méroico }\end{array}$ & 2010 \\
\hline Reunión de lasPartes $\operatorname{COP} 17$ & 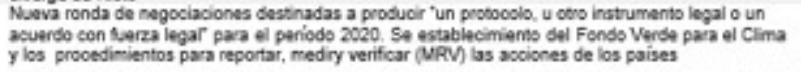 & $\begin{array}{l}\text { Durtan, Sur } \\
\text { Africa }\end{array}$ & 2011 \\
\hline Reunión de lasPartes COP 18 & $\begin{array}{l}\text { Se Aprueba plego: Puerta Climátca de Doha. Promoga hasta } 2020 \text { la vigenela del PK. En Fio do } \\
\text { Janeiro se reunio ta cumbremunsal llamada RiO+20 para el desarrolo sostenible }\end{array}$ & Doha, Catar & 2012 \\
\hline Reunión de lasPartes COP 19 & 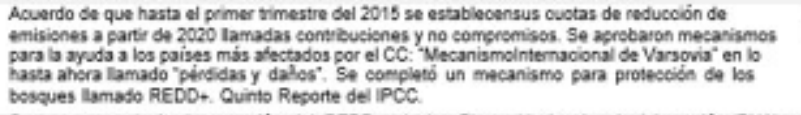 & $\begin{array}{l}\text { Varsovia, } \\
\text { Polonia }\end{array}$ & 2013 \\
\hline Reunión de las Partes COP 20 & Se avanza en la implementasión del REDD, de los Planes Nasionzles de Adaptación (PNA). & Lima, Perí & 2014 \\
\hline Reunión de la Partes COP 21 & 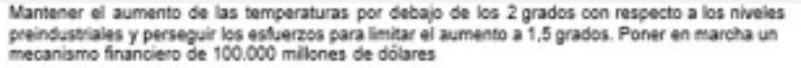 & Paris, Francia & 2015 \\
\hline
\end{tabular}




\footnotetext{
Juan F. Silva y Susan S. Pinto 2015. Cambio Climático: Cronología de negociaciones. Sustentabilidad y desarrollo. http://sustentabilidadydesarrollo.com/2015/01/30/el-cambio-climatico-cronologia-de- negociaciones
}

\subsection{Políticas y normas mundiales sobre Cambio Climático}

$\mathrm{Al}$ darse una alerta importante en cada una de las COP desde 1988 a la fecha, los países han desarrollado una diversidad de políticas para afrontar el Cambio Climático, desde la mitigación a la adaptación. Son diversas las formas y los ámbitos que se consideran, como son: económicos, sociales, científico/tecnológicos, ambientales, educativos, energéticos y hasta políticos, entre otros.

Las políticas que los países desarrollan o deben desarrollar deben tener un contexto sustentable, integral e integrador, social con equidad y género, económico, productivo y ambiental (Fankhauser et al. 2014). En la declaración de la segunda Cumbre sobre legislación en Cambio Climático desarrollado por GLOBE (2015), con una muestra de 99 países analizados a nivel mundial, determinan que:

- Bajo un análisis que data de 1997 al 2014 existen 804 leyes y políticas sobre Cambio Climático, un número muy bajo dado la relevancia del tema, sin embargo ya hay avances. Para 1997 solo habían 54 leyes, para el año 2009 para la reunión de Copenhague habían 426 leyes lo que significa que a partir de las acciones multilaterales para evaluar la situación del cambio climático y sus repercusiones se ha logrado un avance importante.

- Entre el 2013-2014 se han aprobado cerca de 128 nuevas leyes y política, pero el mayor número de instrumentos normativos sacados se dio el 2013 con 82.

- También hay 17 países que no tienen ningún marco normativo aprobado, lo que preocupa de sobre manera es de cómo van afrontar las medidas de mitigación y adaptación a tiempo.

- Otro tema fundamental es que unos 45 países han desarrollado sus objetivos relativo a sus economías, y únicamente 41 países están desarrollando sus políticas hasta los 2020 y 22 países al 2022.

- Las leyes cubren una amplia gama de categorías, incluyendo tanto mitigación y adaptación; la reducción del riesgo de desastres y el desarrollo de resiliencia al riesgo;

- Los países en desarrollo y los mercados emergentes son quienes alentadoramente se encuentran avanzando a un ritmo mayor en la elaboración de leyes y regulaciones en la materia;

- La acumulación actual de toda esta legislación todavía no es suficiente para evitar el aumento de la temperatura media global en 2 grados Celsius, objetivo acordado por la comunidad internacional. (Tabla N ${ }^{\circ}$ ) 
TABLA No2

Descripción de leyes sacadas por algunos países en el 2014

\begin{tabular}{|c|c|c|}
\hline Pais & Leyes y Polvticos & oy Ejecutivo \\
\hline Alomovia & Programa de acción 2020 para la protección del clima & Ejecurivo \\
\hline Angola & $\begin{array}{l}\text { Decreto presidescial 85/14 por el que se apcueba el Estatuto del Ministerio deAmbiente (MINAMB) } \\
\text { Decreto Presidencial I7/14 por el que se aprueba el Programa de Modenizacióndel lnstituto Naciocal de Meterrologia y } \\
\text { Geofisica (INAMET) }\end{array}$ & Ejecurivo \\
\hline Argolige & Onden reguladora sebre la electricidad generada en instalaciones focovoltaicas & Ejecurive \\
\hline $\begin{array}{l}\text { Awtratia } \\
\text { Awtris }\end{array}$ & $\begin{array}{l}\text { Proyecto de ley de enunienda de la iviciativa sobre agricultura de bajo carbono } \\
\text { Ley de eficiencia enengetica }\end{array}$ & $\begin{array}{l}\text { Logislarivo } \\
\text { Logistarivo }\end{array}$ \\
\hline $\begin{array}{l}\text { Bargladesh } \\
\text { Befgica }\end{array}$ & $\begin{array}{l}\text { Maroo de fiscalidad climitica } \\
\text { Ley especial para reformar la financiacióa de las coenunidades y las regiooes, la exsension de la autouomia impositiva de } \\
\text { las regiones y la financiacióa de nuevaseompetencias }\end{array}$ & $\begin{array}{l}\text { Ejocurivo } \\
\text { Logislarivo }\end{array}$ \\
\hline Bolivis & Ley 602 sobse gestion de riesgos & Logitharivo \\
\hline $\begin{array}{l}\text { Bulgaria } \\
\text { Chils }\end{array}$ & $\begin{array}{l}\text { Ley de mitigacióe del cambio clinático } \\
\text { Ley N. - } 20780 \text { sobec el impoesto medioanbiental (tasa al carbono); Plan aacional de adaptación al cumbio climakico }\end{array}$ & $\begin{array}{l}\text { Logislarivo } \\
\text { Logislarivo }\end{array}$ \\
\hline Ching & $\begin{array}{l}\text { Plan de acción estratígica de desamollo esergetico (2014-2020). } \\
\text { Plan zacienal de lucha contra el cambio climsitico (2014-2020) }\end{array}$ & Ejocurivo \\
\hline Colombia & $\begin{array}{l}\text { Ley } 1715 \text { de } 2014 \text { por medio de la cual se regula la ítegración de las energias resovables no convencianales al Sistena } \\
\text { Farergético Nacional }\end{array}$ & Logitiarive \\
\hline $\begin{array}{l}\text { Dinomarca } \\
\text { Eslowaguia }\end{array}$ & $\begin{array}{l}\text { Ley de cambio climático } 2014 \\
\text { Resalución } 148 / 2014 \text {, que establece la estrategia de adaptación }\end{array}$ & $\begin{array}{l}\text { Logislarivo } \\
\text { Ejecurivo }\end{array}$ \\
\hline Espoula & 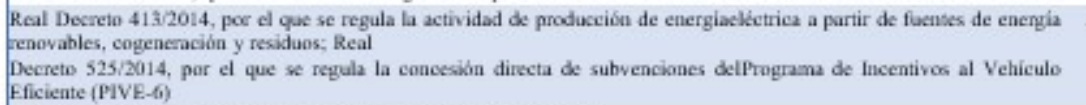 & Ejocurive \\
\hline Francis & Politica marco sobece agricultura, bosques y alimsentacion $2014-1170$ & Logisharivo \\
\hline Filipinas & $\begin{array}{l}\text { Onden ejecutiva } 174 \text { par la que se institucionaliza la gestión de inventarios y el sistema de actificación de las gases de } \\
\text { efecto invernadero }\end{array}$ & Ejecurive \\
\hline Gracia & $\begin{array}{l}\text { Decisióa ministerial } 21906 \text { sobre la coenpeasacióe de industrias íteasivas en carboso (sectares y subsectores) expuestas } \\
\text { a fugas de carbono causadas por los costos ivdirectos del EU ETS }\end{array}$ & Ejecurivo \\
\hline Endonesia & $\begin{array}{l}\text { Plan aacional de desannollo a unedio plaza (2015-2019); } \\
\text { Necva ley geoténaica 21/2014 }\end{array}$ & Ejocurive \\
\hline Irlaruda & $\begin{array}{l}\text { Plan de acción macional sobre eficiencia energética; } \\
\text { Plan de desarrollo de enengia renovable marina }\end{array}$ & Ejecutive \\
\hline Inatia & 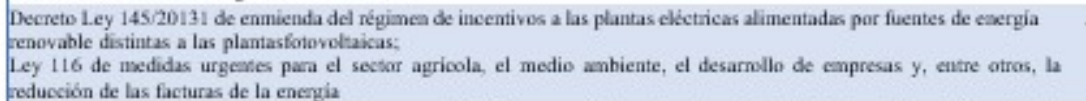 & Logislarive \\
\hline Marruecos & $\begin{array}{l}\text { Real Decreto 1-14-09, que proenulga la L.ey marco } 99-12 \text {, concerniente a la carta nacional del desarnollo medioambiental } \\
\text { y sostenible }\end{array}$ & Ejecurivo \\
\hline $\begin{array}{l}\text { Mongolia } \\
\text { Pakistern }\end{array}$ & $\begin{array}{l}\text { Politica de desannollo ecologico } \\
\text { Pakistin 2025: Una nación, una visice }\end{array}$ & $\begin{array}{l}\text { Ejecurivo } \\
\text { Logislarivo }\end{array}$ \\
\hline Port & 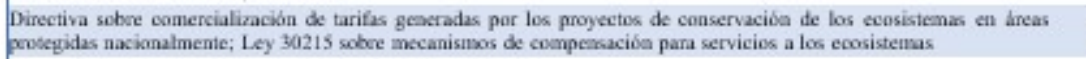 & 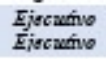 \\
\hline Polonia & Estrategia para la seguridad exergética y el medio ambiente & Ejocurivo \\
\hline $\begin{array}{l}\text { Repribuire } \\
\text { Demberate }\end{array}$ & Ley $14 / 003$ sobre proteccion de la naturaleza; & Logitarivo \\
\hline $\begin{array}{l}\text { Ruraria } \\
\text { Rwia } \\
\text { Seregal } \\
\text { Tertavia } \\
\text { UI } \\
\text { Zimbabue }\end{array}$ & 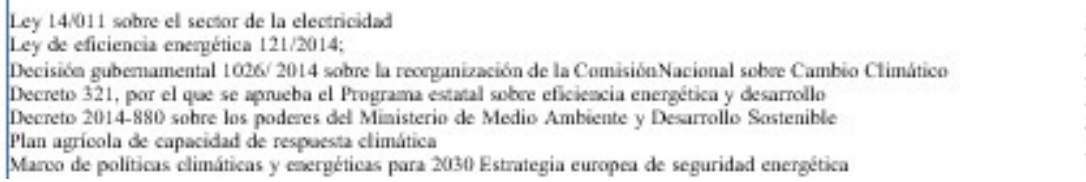 & 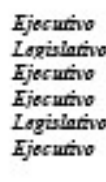 \\
\hline
\end{tabular}

Fankhauser et al. 2014

Los Recursos Naturales engloban todas las posibles estrategias a desarrollarse para afrontar el cambio climático, especialmente porque se tiene que considerar como un medio de vida de las poblaciones humanas, sean estas industrializadas o no. Los efectos negativos sobre los Recursos Naturales puedan traer consigo: sequias, hambruna, desertificación, inundaciones, pérdida de biodiversidad, reducción de la economía de los países en vías de desarrollo, falta de gobernanza y problemas de gobernabilidad.

\subsection{Políticas y normas en el Contienen y el Caribe sobre Cambio Climático.}

En el continente americano y el Caribe, las leyes están muy ligadas al tema de los recursos naturales, biodiversidad, agua y seguridad alimentaria, donde el enfoque es desarrollar medidas de mitigación y adaptación para reducir las líneas de la pobreza y mejorar la condición de vida de las poblaciones más vulnerables, sobre todo a nivel de Sudamérica, Mesoamérica y el Caribe. Los elementos que están en marcha en las políticas públicas para afrontar el Cambio Climático buscan desarrollar competitividad y promover la gestión sustentable, partiendo de: a) Los aspectos políticos; b) Los factores ambientales; c) el ámbito territorial; d) los sistemas agrícolas y pecuarios,; e) ámbitos energéticos; f) Científicos y tecnológicos; g) gestión del conocimientos; h) Gobernanza y Gobernabilidad; i) Equidad y género, entre otras (Tabla 3). 
TABLA No3

Descripción de ámbitos que están relacionados a las políticas públicas con cambio Climática.

\begin{tabular}{|c|c|c|}
\hline Ambitos & Acriones & Politicas \\
\hline $\begin{array}{l}\text { Aspectos } \\
\text { Polífices } \\
\end{array}$ & 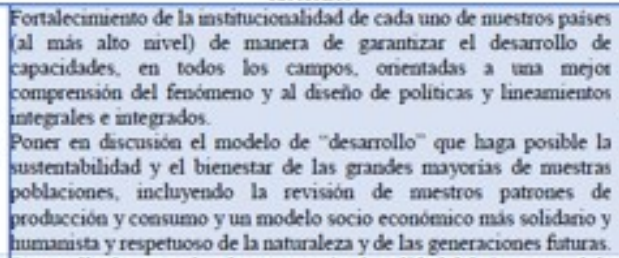 & $\begin{array}{l}\text { Desarrollan estrategias } \\
\text { de fortalecimiento a las } \\
\text { iniciativas. } \\
\text { Generan mecanismos de } \\
\text { incentivos que } \\
\text { promueran }\end{array}$ \\
\hline \multirow[t]{2}{*}{$\begin{array}{l}\text { Factores } \\
\text { Ambiemtaies }\end{array}$} & $\begin{array}{l}\text { Desarrollo de marco legal que garantice la calidad del aire: control de } \\
\text { emisiones de GE en industrias, agricultura, manejo de desechos. }\end{array}$ & $\begin{array}{l}\text { Conservación de los } \\
\text { Recurses Naturales, }\end{array}$ \\
\hline & 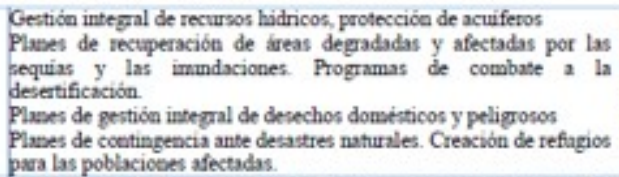 & $\begin{array}{l}\text { Biodiversidad, vida } \\
\text { silvestre, agua. } \\
\text { Estrategias de ireas de } \\
\text { couservaciön } \\
\text { sustentables }\end{array}$ \\
\hline $\begin{array}{r}\text { Gesnioin del } \\
\text { territovio }\end{array}$ & 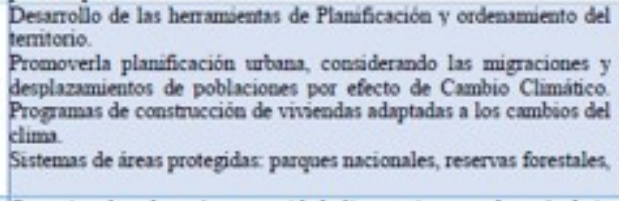 & $\begin{array}{l}\text { Herramientas de } \\
\text { planificacióa del } \\
\text { territorio. } \\
\text { Estrategias de usa } \\
\text { manejo y conservación. } \\
\text { Promover el uso de } \\
\text { acuerdo a las aptitud } \\
\text { natural de los suelos }\end{array}$ \\
\hline $\begin{array}{r}\text { Sistemas } \\
\text { aqricolas } y \\
\text { pecuarios }\end{array}$ & 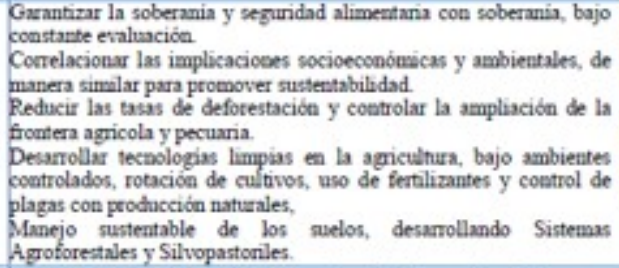 & $\begin{array}{l}\text { Politicas de manejo, } \\
\text { conservacion, uso y } \\
\text { recuperación de suelos. } \\
\text { Recuperación de ireas } \\
\text { degradadas } y \text { mejora o } \\
\text { mastenimieato de la } \\
\text { cobertura. }\end{array}$ \\
\hline $\begin{array}{r}\text { Cientifico } \\
\text { Tecuologico }\end{array}$ & 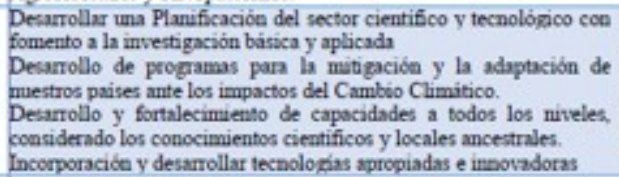 & $\begin{array}{l}\text { Estrategias de fomento a } \\
\text { la imvestigacióne } \\
\text { imovación tecaologica. } \\
\text { Programas de energia } \\
\text { limpia y alternativas } \\
\text { bajas en emisiones }\end{array}$ \\
\hline $\begin{array}{r}\text { Gestion del } \\
\text { conocimientos }\end{array}$ & 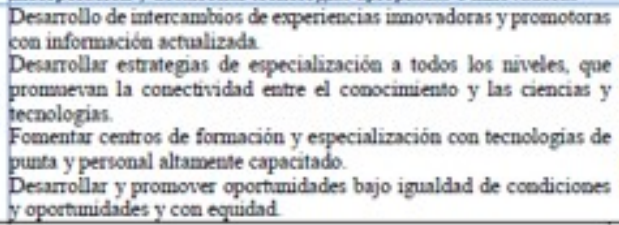 & $\begin{array}{l}\text { Mejera de las curriculas } \\
\text { a todos los aiveles } \\
\text { edacativos. } \\
\text { Fortalecimiento de los } \\
\text { centros de investigación. } \\
\text { Generacion, desarrollo y } \\
\text { fortalecer capacidades }\end{array}$ \\
\hline
\end{tabular}

Propio 2015

La información que presenta el estudio desarrollado por el London School of Economics and political Science/Grantham Research Institute on Climate Change and the Enviroment 4 y analizando la base de datos con la que cuentan5, se pude detectar que a nivel de la región, considerando Norte, Meso, Sudamérica y el caribe los avances en Políticas que combinan Recursos Naturales y Cambio Climático no tiene mucha data (Tabla 4).

A nivel de Sudamérica hay leyes y normativas que están focalizadas en desarrollar sus acciones económicas y productivas para afrontar el cambio climático, generar medidas de mitigación, adaptación y resiliencia, con una data de avances normativa que agarran impulso a partir de los $80 \mathrm{~s}$.

Al parecer, los países han desarrollado en promedio entre 8-9 herramientas legislativas para afrontar el Cambio Climático, lo que no significa que estas sean efectivas a la hora de hacer una análisis de impacto de las mismas, dado los cambios de visón, filosofías, priorizaciones que los estados y naciones tienen en esta última década. A esto hay que sumar las inversiones que se desarrollan y los plazos que se consideran para implementar las políticas, las medidas con las capacidades con las que se cuentan. En términos generales Latinoamérica y el Caribe están recién empezando a invertir en ciencia, tecnologías y desarrollos de medidas innovativas, unos más avanzados que otros, pero no van más allá de las dos últimas décadas. (Tabla N4) 
TABLA N॰4

Relación de normas y leyes que consideran medidas de adaptación y mitigación y los periodos que han tenido

\begin{tabular}{|c|c|c|c|c|}
\hline Pais & Marco de mitigación & Marce de adaptación & $N^{\circ}$ Leges & Periodos \\
\hline Colombia & $\begin{array}{c}\text { Estrategia instifucional para la } \\
\text { articulación de politicas y acciones en } \\
\text { materia de cambio climático } \\
\text { (establecido por la CONPES } 3700 \text { ) } \\
\text { (2011) }\end{array}$ & $\begin{array}{l}\text { Plan Nacional de Adaptación al } \\
\text { Cambio Climático (2012) }\end{array}$ & 10 & $2001-2014$ \\
\hline Belice & $\begin{array}{l}\text { Ley de proteccion medioambiental } \\
\qquad(1992)\end{array}$ & $\begin{array}{l}\text { Estrategia macional de adaptación } \\
\text { para abordar el cambio climárico en } \\
\text { el sector bidrico de Belice (2009) }\end{array}$ & 2 & $1992-2012$ \\
\hline Ecuador & $\begin{array}{l}\text { Estrategia Nacional sobre Cambio } \\
\text { Climatico } 2012 \text { - 2025 (2012) }\end{array}$ & $\begin{array}{l}\text { Estrategia Nacional sobre Cambio } \\
\text { Climático } 2012 \text { - 2025 (2012) }\end{array}$ & 8 & $2009-2013$ \\
\hline Brasil & $\begin{array}{c}\text { Politica nacional sobre cambio } \\
\text { climático (establecida por la Ley } \\
12187 / 2009)(2009)\end{array}$ & $\begin{array}{c}\text { Politica nacional sobre cambio } \\
\text { climático (establecida por la Ley } \\
12187 / 2009)(2009)\end{array}$ & 12 & $2001-2013$ \\
\hline Perú & $\begin{array}{c}\text { Estrategia nacional sobre cambio } \\
\text { climático (2003) }\end{array}$ & $\begin{array}{c}\text { Estrategia nacional sobre cambio } \\
\text { climático (2003) }\end{array}$ & 6 & $1980-2013$ \\
\hline Bolivia & Ninguno & Ninguno & 6 & $1996-2014$ \\
\hline Argentina & Ninguno & Ninguno & 9 & $1998-2015$ \\
\hline Chile & $\begin{array}{l}\text { Plan de acción nacional de cambio } \\
\text { climático 2008-2012 (2008) }\end{array}$ & $\begin{array}{c}\text { Plan nacional de adaptación al } \\
\text { cambio climático (2014) }\end{array}$ & 11 & $2000-2014$ \\
\hline El Salvador & $\begin{array}{l}\text { El Salvador Estrategia Nacional de } \\
\text { Cambio Climatico (2013) }\end{array}$ & $\begin{array}{c}\text { Estrategia Nacional de Cambio } \\
\text { Climitico (2013) }\end{array}$ & 6 & $2005-2013$ \\
\hline Guatemala & $\begin{array}{l}\text { Ley marco para regular la reducción } \\
\text { de la vulnerabalidad, la adaptación } \\
\text { obligatoria ante los efectos del cambio } \\
\text { climático y la mitigación de gases de } \\
\text { efecto invernadero (2013). }\end{array}$ & $\begin{array}{l}\text { Ley marco para regular la reducción } \\
\text { de la vulnerabilidad, la adaptación } \\
\text { obligatoria ante los efectos del } \\
\text { cambio climático y la mitigación de } \\
\text { gases de efecto invernadero (2013). }\end{array}$ & 7 & $2003-2013$ \\
\hline Costa Rica & $\begin{array}{c}\text { Estrategia Nacional de Cambio } \\
\text { Climitico (2008) }\end{array}$ & $\begin{array}{c}\text { Estrategia Nacional de Cambio } \\
\text { Climitico (2008) }\end{array}$ & 9 & $1990-2013$ \\
\hline Cuba & $\begin{array}{l}\text { Estrategia Ambiental Nacional 2011- } \\
\qquad 2015 \text { (2010) }\end{array}$ & $\begin{array}{c}\text { Cuba Estrategia Ambiental Nacional } \\
2011-2015 \text { (2010) Estrategia } \\
\text { Ambiental Nacional 2011-2015 } \\
\text { (2010) }\end{array}$ & 7 & $1993-2010$ \\
\hline Guayanas & $\begin{array}{l}\text { Estrategia de desarrollo bajo en } \\
\text { carbono (2009, actualizado en 2013) }\end{array}$ & $\begin{array}{l}\text { Estrategia de desarrollo bajo en } \\
\text { carbono (2009, actualizado en 2013) }\end{array}$ & 2 & 2009 \\
\hline Jamaica & Ninguno & Ninguno & 3 & $2002-2009$ \\
\hline $\begin{array}{r}\text { Trinidad y } \\
\text { Tobago }\end{array}$ & $\begin{array}{c}\text { Politica nacional sobre cambio } \\
\text { climático (2011) }\end{array}$ & $\begin{array}{l}\text { Politica nacional sobre cambio } \\
\text { climático (2011) }\end{array}$ & 6 & $2000-2012$ \\
\hline $\begin{array}{r}\text { Republica } \\
\text { Dominicana }\end{array}$ & $\begin{array}{l}\text { Estrategia Nacional de Desarrollo } \\
\text { (2012); Plan de Desarrollo económico } \\
\text { Compatible con el Clima de la } \\
\text { Repuiblica Dominicana (2011) }\end{array}$ & Ninguno & 10 & $2002-2014$ \\
\hline Canadà & Nenguano & Ninguno & 3 & $1992-2001$ \\
\hline $\begin{array}{r}\text { Estados } \\
\text { Unidos }\end{array}$ & Ninguno & $\begin{array}{l}\text { Orden ejecutiva 13653: Preparando } \\
\text { a Estados Unidos para los impactos } \\
\text { del cambio climático (2013) }\end{array}$ & 10 & $1963-2015$ \\
\hline México & $\begin{array}{l}\text { Ley General de Cambio Climitico } \\
\text { (2012) }\end{array}$ & $\begin{array}{l}\text { Ley General de Cambio Climático } \\
\qquad(2012)\end{array}$ & 6 & $1980-2013$ \\
\hline
\end{tabular}

Base de datos del London School of Economics and political Science/ Grantham Research Institute on Climate Change and the Enviroment. 2015

\subsection{Desglose las legislaciones en algunos países del contienen.}

A continuación se hace un desglose de las legislaciones que los países del continente americano han desarrollado, según el Estudio sobre legislación de cambio climático: Informe sobre la legislación de cambio climático en 99 países (2015). Es importante que en un futuro cercano hagamos un análisis con la información, evaluemos los avances, los retrocesos, los cuellos de botella y lecciones aprendidas, en búsqueda de procesos acertados.

\subsubsection{Argentina}

Normativas 9: 1998-2015.

- Decreto No140: Programa Nacional y uso racional y eficiente de la energía (Argentina/ 2007 / Ejecutivo) - Ley N 25.019: Régimen Nacional de energía eólica y solar (Argentina / 1998 / Legislativo)

- Ley N ${ }^{\circ}$ 26.093: Régimen de Regulación y Promoción para la Producción y Uso Sustentable de Biocombustibles (Argentina / 2006 / Legislativo)

- Ley N 26.123 (2006) Promoción de la Energía del Hidrógeno (Argentina / 2006 / Legislativo) 
- Ley N²6.190 Régimen de Fomento Nacional para la Producción y Uso de Fuentes de Energía Eléctrica Renovable (Argentina / 2007 / Legislativo)

- Ley N²6.190 Régimen de Fomento Nacional para la Producción y Uso de Fuentes de Energía Eléctrica (Argentina / 2007 / Legislativo)

- Ley $N^{\circ}$ 26.473: Prohibición de la importación y comercialización de lámparas incandescentes de uso residencial general (Argentina / 2010 / Legislativos)

- Ley N²7.191: Energía Renovable (Argentina / 2015 / Legislativo)

- Decreto Nacional No 1070-1005: Creación del Fondo Argentino de Carbono (Argentina / 2005 / Ejecutivo)

\subsubsection{Belize}

Normativas 2: 1992-2012

- Estrategia Nacional de Adaptación al abordar el cambio climático en el sector hídrico de Belice (Belice / 2009 / Ejecutivo)

- Estrategia Nacional de Energía Sostenible 2012-2033: Ministerio de Energía, Ciencia y Tecnología y el Plan Estratégico 2012-2017 de Asuntos Públicos (Belice / 2012 / Ejecutivo).

\subsubsection{Bolivia}

\section{Normativas 6: 1996-2014}

- Decreto Supremo N²9466: Programa Nacional de Eficiencia Energética (Bolivia / 2008 / Ejecutivo)

- Ley $N^{\circ}$ 1700: Ley Forestal (Bolivia / 1996 / Legislativo)

- Ley o N 305: Sobre el Uso Eficiente y Racional de la Energía (Bolivia / 2012 / Legislativo)

- Ley N 602: Gestión de Riesgos (Bolivia / 2014 / Legislativo)

- La Ley N 300: Marco de la Madre Tierra y el Desarrollo Integral para Vivir Bien (Bolivia / 2012 / Legislativo)

- Ley N071: Los Derechos de la Ley Madre Tierra (Bolivia / 2010 / Legislativo).

\subsubsection{Brasil}

Normativas 12: 2001-2013

- Decreto N 6263/2007: Creación del Comité Interministerial sobre el Cambio Climático (CICC) / 2007 / Ejecutivo)

- Decreto de Creación de la Comisión Interministerial sobre el Cambio Climático (CIMGC) (Brasil / 1999 / Ejecutivo)

- Ley N 10294/2001: Establecimiento de la Conservación Nacional y Política de Uso Racional de Energía (Brasil / 2001 / Legislativo)

- Ley N ${ }^{\circ}$ 10438/2002: Establecimiento del Programa de Incentivos a las Fuentes Alternativas de Electricidad (PROINFA) (Brasil / 2002 / Legislativo)

- Ley N 11097/2005: Ley del Biodiesel (Brasil / 2005 / Legislativo)

- Ley N ${ }^{\circ}$ 11284/2006: Establecimiento de la Gestión de los Bosques Públicos. Servicio Forestal Brasileño y el Fondo Nacional de Desarrollo Forestal (Brasil / 2006 / Legislativo)

- Ley No 12144/2009 y el Decreto N 7343/2010: Creación del Fondo Nacional para el Cambio Climático (NFCC) (Brasil / 2009 / Legislativo)

- Ley N 12187/2009: Establecimiento de la Política Nacional Sobre el Cambio Climático (PNCC), Regulado Decreto 7390/2010 (Brasil / 2009 / Legislativo / Mitigación y Adaptación marco)

- Ley N ${ }^{\circ}$ 12.805: Establecimiento de la Política Nacional de Integración Agricultura - Ganadería - Bosque (Brasil / 2013 / Legislativo)

- Plan Nacional de Eficiencia Energética (Brasil / 2011 / Ejecutivo)

- Plan Nacional de Energía 2030 (PNE 2030) (Brasil / 2007 / Ejecutivo)

- Plan Nacional sobre el Cambio Climático (Brasil / 2008 / Ejecutivo).

\subsubsection{Canadá}




\section{Normativas 3: 1992-2001}

- Creación de la Fundación Canadiense para el Desarrollo de Tecnología Sostenible (SC 2001, c . 23 ) (Canadá / 2001 / Legislativo )

- Ley de Eficiencia Energética (C.C. 1992 , c. 36 ) (Canadá / 2008 / Legislativo )

- Ley Canadiense de Protección Ambiental 1999 (CEPA 1999) ( SC 1999 , c . 33 ) (Canadá / 2000 /

Legislativo ), para la gestión y el control de sustancias tóxicas.

\subsubsection{Chile}

Normativas 11: 2000-2014

- Ley N 19.657 y Decreto N 114: Uso de Energía Geotérmica (Chile / 2000 / Legislativo )

- Ley N 19.940 de modificación a la Ley General de Servicios Eléctricos (LGSE) de 1982 (Chile / 2004 / Legislativo )

- Ley N²0.257: Uso de Energías Renovables No Convencionales (Chile / 2008 / Legislativo )

- Ley N²0.365: Exención Contributiva para Sistemas Termales Solares (Chile / 2010 / Legislativo)

- Ley N 20.571: Sobre la Tasa Fiscal de Medioambiental (impuesto sobre el carbono) ( Chile / 2014 / Legislativo )

- Ley N²0.571: Regulación del Pago por Tarifas Eléctricas de Generadores Residenciales (Chile / 2012 / Legislativo )

- Plan Nacional de Acción de Cambio Climático 2008-2012 (Chile / 2008 / Ejecutivo / Mitigación marco)

- Plan Nacional de Adaptación al Cambio Climático (Chile / 2014 / Ejecutivo / Marco de Adaptación )

- Estrategia Nacional de Energía 2012-2030 (Ejecutivo Chile 2008)

- Estrategia Nacional sobre Bosques y Cambio Climático (Chile / 2013 / Ejecutivo)

- Resolución N $N^{\circ}$ 370: Regulación de las Subvenciones para las Líneas de Transmisión de Energía para Facilitar el Acceso a la Red para Instalaciones de Energías Renovables (Chile / 2012 / Ejecutivo)

\subsubsection{Colombia}

\section{Normativas 10: 2001-2014}

- Estrategia de Desarrollo colombiano de Bajas Emisiones de Carbono (Colombia / 2012/ Ejecutivo)

- Documento CONPES N ${ }^{\circ}$ 3700: Estrategia Institucional para la Articulación de Políticas y Acciones en el Cambio Climático (Colombia / 2011 / Ejecutivo)

- Ley N 1450: Plan Nacional de Desarrollo 2010-2014 (Colombia / 2011 / Legislativo)

- Ley N ${ }^{\circ}$ 1523: Adopción de la Política Nacional de Gestión de Riesgos y el Sistema Nacional de Gestión de Riesgos (Colombia / 2012 / Legislativo)

- Ley N ${ }^{\circ}$ 1715: Regulación de la Integración y Promoción de las Energías Renovables No Convencionales al Sistema Energético Nacional (Colombia / 2014 / Legislativo )

- Ley 697, la promoción del uso racional y eficiente de la energía y el uso de otras fuentes de energía no convencionales. (Colombia / 2001 / Legislativo )

- Ley N 788/2002: Reforma Tributaria (Colombia / 2002 / Legislativo )

- Plan Nacional de Energía 2006-2025 (Colombia / 2006 / Ejecutivo)

- Plan Nacional de Adaptación al Cambio Climático (Colombia / 2012 / Ejecutivo / Marco de Adaptación)

- Resolución N 18-0919 del Ministerio de Minas y Energía: Adopción del Plan de Acción Indicativo 2010-2015 para Desarrollar el Programa de Uso Racional y Eficiente de la Energía y de Otras Fuentes de Energía No Convencionales (Colombia / 2010 / Ejecutivo).

\subsubsection{Costa Rica}

Normativa 9: 1990-2013

- Decreto N 35.091: Reglamento de Biocombustibles (Costa Rica / 2009 / Ejecutivo) 
- Decreto N 36823 - MINAET: Creación y Regulación del Comité Interministerial de Cambio Climático (Costa Rica / 2012 / Ejecutivo)

- Ley N 7200 : Ley de Energía (Ley No 7200) (Costa Rica / 1990 / Legislativo)

- Decreto N ${ }^{\circ}$ 37352: Establecimiento de la Agencia de Apoyo Ejecutivo para el Desarrollo y Aplicación de la Estrategia REDD de Costa Rica (Costa Rica / 2012 / Ejecutivo)

- Ley Forestal No 7575 (Costa Rica / 1996 / Legislativo)

- Decreto N ${ }^{\circ}$ 37296-MINAE: Creación del Mercado Voluntario de Carbono (Costa Rica / 2013/ Ejecutivo

- Estrategia Nacional de Cambio Climático (NCCS) (Costa Rica / 2008 / Ejecutivo / Mitigación y Adaptación marco)

- Plan Nacional de Energía 2008-2021 (Costa Rica / 2008 / Ejecutivo)

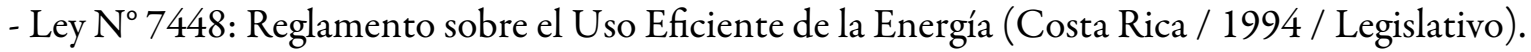

\subsubsection{Ecuador}

Normativa 8:2009-2013

- Decreto $N^{\circ}$ 1.303: Mandato Biodiesel (Ecuador / 2012 / Ejecutivo)

- Decreto N 495: Creación del Comité Interinstitucional sobre el Cambio Climático (Ecuador / 2010 / Ejecutivo)

- Decreto Nº04/11: Sistema de Incentivos para las Energías Renovables No Convencionales (Ecuador / 2011 / Ejecutivo)

- Acuerdo $N^{\circ}$ 089: Reglamentación Nacional de Implementación de Acciones de Mitigaciones Apropiadas NAMAs (Ecuador / 2013 / Ejecutivo)

- Acuerdo N ${ }^{\circ}$ 33: Normas para la Implementación del Mecanismo REDD en Ecuador (Ecuador / 2013 / Ejecutivo)

- Plan Nacional para el Buen Vivir (2013-2017) (Ecuador / 2013 / Ejecutivo).

- Decreto $N^{\circ} 1815$ y Acuerdo $N^{\circ}$ 095: Estrategia Nacional de Mitigación y Adaptación al Cambio Climático (Ecuador / 2009 / Ejecutivo)

- Decreto No 676 y N 741: Programa RENOVA: Reducción del Consumo de Energía y Aumento la Eficiencia Energética en+ el Ecuador (Ecuador / 2012 / Ejecutivo).

\subsubsection{Estados Unidos de Norte América}

\section{Normativa 10: 1963-2015}

- Ley de Reinversión y Recuperación del Programas de Eficiencia Energética y Energías Renovables (Estados Unidos / 2009 / Legislativo)

- Ley de Aire Limpio para el Controlar de la Contaminación del Aire a Nivel Nacional (Estados Unidos / 1963 / Legislativo)

- Ley de Autorización de Gastos de la Defensa Nacional Duncan Hunter para el año fiscal 2009: Disposiciones Encaminadas a la Eficiencia Energética, Uso de Energías Renovables y de Fuentes Alternativas en las Fuerzas Armadas (Estados Unidos / 2008/ Legislativo).

- Ley de Independencia Energética y Seguridad 2007 (Estados Unidos / 2007 / Legislativo)

- Ley de Política Energética 2005: Ley de Energía (Estados Unidos / 2005 / Legislativo)

- Orden Ejecutiva N ${ }^{\circ}$ 13423: Fortalecimiento Federal del Medio Ambiente, Energía y Gestión de Transporte (Estados Unidos / 2007 / Ejecutivo)

- Orden Ejecutiva N 13514: Liderazgo Federal en Medio Ambiente, Energía y Desempeño Económico (Estados Unidos / 2009 / Ejecutivo)

- Orden Ejecutiva $N^{\circ}$ 13653: Preparación de los Estados Unidos para los Impactos del Cambio Climático (Estados Unidos / 2013 / Ejecutivo / Marco de Adaptación)

- Orden Ejecutiva N 13693: Planificación Federal de Sostenibilidad en la Próxima Década (Estados Unidos / 2015 / Ejecutivo), 
- Ley de Energía, Alimentos y Conservación N² 2008 (revisada en 2014) (Estados Unidos / 2008 / Legislativo).

\subsubsection{Cuba}

Normativa 7: 1993-2010

- Ley $N^{\circ} 75$ de la Defensa Civil y el Decreto Ley N 170: Sistema de Medidas de Defensa Civil (gestión de desastres como respuesta a eventos extremos frecuentes) (Cuba / / Legislativo 1997)

- Decreto Ley N 147: Reorganización de Órganos Administrativos de las Centrales Estatales: Creación del Ministerio de Ciencias, Tecnología y Medio Ambiente Responsables de de las Políticas de Cambio Climático (Cuba / 1994 / Legislativo)

- Programa de Desarrollo de las Fuentes de Energía Nacional (Cuba / 1993 / Ejecutivo)

- Estrategia Nacional Ambiental 2011-2015 (Cuba / 2010 / Ejecutivo)

- Grupo Nacional para el Desarrollo Acelerado de las Energías Renovables y la Eficiencia Energética (Cuba / 2007 / Ejecutivo)

- Resolución N 136/09: Regulación Técnica de la Eficiencia Energética en los Aparatos Eléctricos (Cuba / 2009 / Ejecutivo)

- Programa Estatal de Ahorro de Energía del Ministerio de Educación (Cuba / 1997 / Ejecutivo).

\subsubsection{El Salvador}

Normativa: $2005-2013$

- Política Nacional de Energía 2010-2024 (El Salvador / 2010 / Ejecutivo)

- Decreto N 714: Modificación de la Ley General de Educación (El Salvador / 2011 / Legislativo)

- Decreto N ${ }^{\circ}$ 777: Protección Civil, Prevención de Desastres y Mitigación (El Salvador / 2005 / Legislativo)

- Ley N ${ }^{\circ}$ 462: Incentivos Fiscales para una Mayor Utilización de las Energías Renovables Dentro de la Ley de Generación de Electricidad (El Salvador / 2007 / Legislativo)

- Política Ambiental Nacional (El Salvador / 2012 / Ejecutivo)

- Estrategia Nacional de Cambio Climático (NCCS) (El Salvador / 2013 / Ejecutivo / Mitigación y Adaptación marco).

\subsubsection{Guatemala}

Normativa 7: 2003-2013

- Acuerdo de Gobierno N³29-2009: Política de Cambio Climático (Guatemala / 2009 / Ejecutivo)

- Política Energética 2013-2027 (Guatemala / 2013 / Ejecutivo)

- Decreto No 7-2013: Ley Marco para Regular la Reducción de la vulnerabilidad, Adaptación Obligatoria a los Efectos del Cambio Climático y la Mitigación de los Efectos de Gases de Efecto Invernadero (Guatemala / 2013 / Legislativo / Mitigación y Adaptación marco)

- Decreto N ${ }^{\circ}$ 52-2003: Ley de Incentivos para el Desarrollo de Proyectos de Energía Renovable (Guatemala / 2003 / Legislativo)

- Acuerdo N²20-2011: Política Nacional de Biodiversidad (Guatemala / 2011 / Ejecutivo)

- Acuerdo N²58-2010: Política Nacional de Producción Limpia (Guatemala / 2010 / Ejecutivo)

- Acuerdo N³28-2009: Administración Nacional Integrada de Políticas Marinas de Zonas Costero (Guatemala / 2009 / Ejecutivo).

\subsubsection{Guayanas}

Normativas 2: 2009

- Estrategia de Desarrollo de Bajas Emisiones de Carbono (Guyana / 2009 / Ejecutivo / Mitigación y Adaptación marco)

- Estrategia Nacional de Adaptación al Cambio Climático en el Sector Agrícola de Guyana (Guyana / 2009 / Ejecutivo)

\subsubsection{Jamaica}




\section{Normativa 3: 2002-2009}

- Política Nacional de Energía de largo plazo 2009 2030: Ministerio de Energía y Minas (Jamaica / 2010 / Ejecutivo)

- Autoridad de Conservación y Regulación de Recursos Naturales (Calidad del aire) Reglamentos (Jamaica / 2002 / Legislativo)

- Visión 2030 Jamaica: Mitigación y Adaptación (Jamaica / 2009 / Ejecutivo)

\subsubsection{México}

Normativa 6: 1980-2013

- Acelerada Depreciación de las Inversiones de Beneficios Ambientales (México / 2005 / Legislativo.

- Ley de Promoción de Bioenergía y Desarrollo (México / 2007 / Legislativo)

- Ley para Uso de Energía Sostenible (LASE) (México / 2008 / Legislativo)

- Ley para el Aprovechamiento de Energías Renovables y Financiamiento de la Transición Energética

(LAERFTE) (México / 2008 / Legislativo)

- Estrategia Nacional de Cambio Climático ( México / 2013 / Ejecutivo)

- Ley Especial de Impuestos sobre Producción y Servicios (impuesto sobre el carbono) (México / 1980 / Legislativo)

\subsubsection{Perú}

\section{Normativa 10: 2002-2014}

- Creación del Régimen Temporal para la Renovación de Vehículos Automotores con el fin de promover el cambio de la matriz energética, el Decreto Ejecutivo No 213-2007- EF (Perú / 2007 / Ejecutivo)

- Decreto N 26-2014-SERNANP: Directiva Nacional de Comercialización y Generación de Tasas por Proyectos de Conservación de Ecosistemas en Áreas Protegidas (Perú / 2014 / Ejecutivo)

- Ley $N^{\circ} 28.054$ y Decreto $N^{\circ}$ 013-2005 del reglamento: Promover un Mercado de Combustibles y Biocombustibles (Perú / 2003 / Legislativo)

- Ley N² 27.345 y Decreto Nº53-2007-EM: Promoción de Uso Eficiente de la Energía (Perú / 2000 / Legislativo)

- Ley N 30.215: Mecanismos de Compensación por Servicios de los Ecosistemas (Perú

/ 2014 / Legislativo)

- Decreto N 008 -2010-MINAN: Plan Nacional para la Conservación de Bosques para la Mitigación de Cambio Climático (Perú / 2010 / Ejecutivo)

- Decreto Nº 086-2003-PCM: Estrategia Nacional de Cambio Climático (Perú / 2003 / Ejecutivo)

- Ley N 27.867: Ley Orgánica de Gobiernos Regionales de Descentralización de la Gobernabilidad (Perú / 2002 Legislativo)

- Decreto $N^{\circ}$ 1058: Promoción de la Actividad de Inversión para la Generación de Electricidad a Partir de Energía Hidroeléctrica y Otras Fuentes Renovables (Perú / 2008 / Legislativo)

- Decreto N 1002: Promoción de la Inversión para la Generación de Electricidad a Partir de Energías Renovables (Perú / 2008 / Legislativo).

\subsubsection{República Dominicana}

\section{Normativa 6: 2000-2012}

- Decreto N ${ }^{\circ}$ 601-08: Establecimiento del Consejo Nacional Sobre el Cambio Climático y Mecanismo de Desarrollo Limpio (República Dominicana / 2008 / Ejecutivo),

- Ley Nº 1-12: Estrategia Nacional de Desarrollo (República Dominicana / 2012 / Legislativo)

- Ley N 112-00: Ley de hidrocarburos (República Dominicana / 2000 / Legislativo)

- Ley N 125-01: Ley General de Electricidad (República Dominicana / 2001 / Legislativo)

- Ley N 57-07 sobre Energía Renovable (apoyado por el 2008 de Energías Renovables Reglamento No. 202-08) (República Dominicana / 2007 Legislativo) 
- Estrategia Nacional para el Fortalecimiento de los Recursos Humanos y Habilidades para Avanzar a un Desarrollo Verde, con bajas emisiones y Resiliencia Climático (República Dominicana / 2012 / Ejecutivo / Mitigación y Adaptación Marco).

1-4-18 Trinidad y Tobago

Normativa 6: 2000-2011

- Ley N 13/1963; Capítulo 77:01: Modificada por la Ley 46 de 2013: Esta Establece el Fondo Verde para ayudar financieramente a las organizaciones y grupos de la comunidad que se dedican a actividades relacionadas con la remediación, la reforestación y la conservación del medio ambiente (Trinidad y Tobago / 2000 / Legislativo)

- Plan de Desarrollo Económico Integral de Tobago: limpio, verde, seguro y sereno (Trinidad y Tobago / 2006 / Ejecutivo)

- Innovación para la prosperidad duradera: Mediano Plazo Policy Framework (MPMP) 2011-2014 (Trinidad y Tobago / 2011 / Ejecutivo)

- Política Nacional de Cambio Climático (Trinidad y Tobago / 2011 / Ejecutivo / Mitigación y Adaptación marco)

- Política Nacional del Ambiente (Trinidad y Tobago / 2006 / Ejecutivo)

- Política Forestal Nacional (Trinidad y Tobago / 2011 / Ejecutivo)

2 Una propuesta legislativa práctica para Bolivia

La legislación de Bolivia respecto a los recursos Naturales y el Cambio Climático, es una propuesta exterior denominada: "La Propuesta de Bolivia - Vida sustentable del Bosque"; basada en: a) la no mercantilización de las funciones ambientales de los bosques; $b$ ) manejo

integral y sustentable de los bosques (incluyendo tierra, agua y biodiversidad) con el énfasis en prácticas productivas locales y tradicionales; c) promoción de las múltiples funciones de los bosques: económico, social, ambiental y cultural; d) complementariedad de derechos, obligaciones y deberes para el manejo integral de los bosques, destacando los derechos de los pueblos indígenas originarios campesinos y los derechos de la Madre Tierra; e) reconocimiento del doble rol de los bosques en mitigación y adaptación al cambio climático (Pacheco 2014).

A partir de la nueva constitución Política del Estado Plurinacional, la Ley marco de la Madre Tierra 3000 y la Ley N ${ }^{\circ}$ 071: sobre los Derechos de la Ley Madre Tierra, aprobada el 2012 por la Asamblea Legislativa Plurinacional, armoniza la posición internacional boliviana en bosques con la agenda plurinacional, promoviendo la construcción de una visión descolonizadora sobre los bosques. Aspecto central de la Ley 300 es la construcción de un nuevo enfoque basado en la creación y fortalecimiento de "sistemas productivos sustentables", reto que también es asumido en la Agenda Patriótica 2025 de Bolivia. Esta Ley pone en marcha una nueva visión para el manejo integral y sustentable de los bosques en un contexto de cambio climático que está basada en la complementariedad de derechos del ser humano y la Madre Tierra (Art. 9).

La Ley No. 300 Marco de la Madre Tierra plantea que un derecho no puede materializarse sin los otros o no puede estar sobre los otros, implicando la interdependencia y apoyo mutuo como ser: i) derechos de la Madre Tierra como sujeto colectivo de interés público; ii) derechos colectivos de las naciones y pueblos indígena originario campesinos, comunidades interculturales y afrobolivianas; iii) derechos fundamentales, civiles, políticos, sociales, económicos y culturales del pueblo boliviano para Vivir Bien a través de su desarrollo integral; y iv) derecho de la población urbana y rural a vivir en una sociedad justa, equitativa y solidaria sin pobreza material, social y espiritual (Pacheco 2014).

Este proceso se consolidad a partir del 2010, a través de:

- Convocatoria que desarrolla Bolivia a las naciones del mundo donde se convierte en la sede para la "Conferencia Mundial de los Pueblos sobre Cambio Climático y Derechos de la Madre Tierra, llevada a efecto en la población de Tiquipaya, en abril 2010, la que reúne a unas 30.000 personas entre representantes de gobiernos, organizaciones sociales, naciones y pueblos del mundo, donde se expresa "la condena a los 
mecanismos de mercado, como el mecanismo de REDD (Reducción de emisiones por la deforestación y degradación de bosques) y sus versiones $+\mathrm{y}++$. (CAIT, 2010)

- Desarrollo II Conferencia Mundial de los Pueblos Sobre Cambio Climático y Defensa de la Vida, donde se saca la Declaración como propuesta para las negociaciones internacionales de las Conferencias de Partes de las Naciones Unidas sobre cambio climático, medio ambiente, desarrollo sostenible y otros escenarios relevantes, así como para la agenda permanente de los pueblos para la defensa de la vida.

- De acuerdo al mandato de la conferencias Mundial de los pueblos, Bolivia rechaza los acuerdos de la COP 16 desarrollada en Cancún - México, expresando una oposición a los procesos de mercantilización de las funciones ambientales, incluido REDD+.

- El 2011 Bolivia formula la propuesta denominada: "Vida Sustentable del Bosque", resultados de un proceso amplio de consultas para dar una alterantiva a REDD +. Es aquí donde se expresa: a) No mercantilización de las funciones ambientales de los bosques; b) Manejo integral y sustentable de los bosques (incluyendo tierra, agua y biodiversidad) con énfasis en prácticas productivas locales y tradicionales; c) Promoción de las múltiples funciones de los bosques: económicas, sociales, ambientales, y culturales; d) Complementariedad de derechos, obligaciones y deberes para el manejo del bosque, destacando los derechos de los pueblos indígena originario campesinos y los derechos de la Madre Tierra; e) Reconocimiento del doble rol de los bosques en mitigación y adaptación al cambio climático.

La propuesta de "Vida Sustentable del Bosque" se presentó en la COP17 de Sudáfrica, recibiendo el apoyo mayoritario de los países del mundo, ante la falta de propuestas que refuercen las negociaciones internacionales sobre cambio climático puesto que el énfasis del grupo de trabajo en bosques "Policy approaches and positive incentives on issues relating to 9 reducing emissions from deforestation and forest degradation in developing countries; and the role of conservation, sustainable management of forests and enhancement of forest carbon stocks in developing countries" estuvo principalmente dirigido a apoyar los compromisos de reducción de las emisiones de efecto invernadero en los países desarrollados como parte de sus acciones de mitigación al cambio climático con la participación de los países en desarrollo a través del establecimiento de mercados globales de carbono.

- La decisión 2/CP.17 de Sudáfrica, en el marco del grupo de trabajo en bosques recupera en su totalidad el enfoque de "Vida Sustentable del Bosque" presentado por Bolivia, donde se dispone, que:

"Los enfoques no basados en el mercado, tales como los enfoques conjuntos de mitigación y adaptación para el manejo integral y sustentable de los bosques como una alternativa de no mercado que respalde y fortalezca la gobernanza, la aplicación de las salvaguardias mencionadas en el párrafo 2 (c-e) del apéndice I de la decisión 1/ CP.163, y las múltiples funciones de los bosques, podrian ser desarrollados".

La propuesta boliviana busca desarrollar un instrumento que fomente el rol de los bosques en la mitigación y adaptación al cambio climático en el contexto de la Convención Marco de Naciones Unidas (CMNUCC), para la constitución de un instrumento que no esté basado en los mercados y que permita articular los objetivos y metas de las diferentes Convenciones de Naciones Unidas, como ser. De esta forma el Mecanismo Conjunto tiene que ver con la temática del cambio climático pero también con la conservación y manejo sustentable de la diversidad biológica y la reducción de los procesos de desertificación, creando sinergias en el cumplimiento de los alcances de estas diferentes Convenciones que ha suscrito Bolivia (Pacheco 2014). En este sentido:

- La propuesta se concibe el propósito de avanzar en la implementación de la sugerencia de la Declaración de Rio+20 "El futuro que queremos" (junio de 2012), donde se llama por la urgente implementación del "Instrumento Legal No Vinculante en todos los Tipos de bosques", así como la Declaración Ministerial del segmento de alto nivel de la novena sesión del Foro en Bosques de Naciones Unidas, que está enfocado a poner en marcha acciones para el manejo sustentable de los bosques.

- Se propone avanzar en la sinergia propuesta por la Decisión VIII/30 del Convenio sobre Diversidad Biológica, en cuanto a las sinergias entre la conservación de la biodiversidad 
y la mitigación y adaptación al cambio climático, así como las metas 5, 7, 11, 14 y 15, relacionadas con los bosques y adoptadas por la última Conferencia de las Partes de la CBD.

- Los acuerdos y sugerencias de las negociaciones internacionales sobre bosques, cambio climático y diversidad biológica, pone en marcha la propuesta del enfoque y mecanismo: "Mecanismo Conjunto de Mitigación y Adaptación para el Manejo Integral y Sustentable de los Bosques y Madre Tierra”.

- Cumplir las metas sobre mitigación y adaptación al cambio climático de forma simultánea, pero como parte de una propuesta de no mercantilización de los bosques y fomentando el manejo integral y sustentable de los bosques, en sinergia con la protección y manejo sustentable de otros componentes de la Madre Tierra (tierra, agua, bosques y biodiversidad) y el desarrollo de sistemas productivos sustentables.

El Mecanismo Conjunto de Mitigación y Adaptación para el Manejo Integral y Sustentable de los Bosques y la Madre Tierra, tiene por objetivos y metas:

Avanzar de manera efectiva en la mitigación y adaptación al cambio climático a través del manejo integral y el aprovechamiento sustentable de los bosques y los sistemas de vida de la Madre Tierra, fomentando la conservación y restauración de los sistemas de vida, el manejo, conservación y protección de la biodiversidad, facilitando la transición hacia usos más óptimos del suelo mediante el desarrollo de sistemas productivos más sustentables que reducen la deforestación y degradación forestal.

- Ser la principal herramienta para la implementación del marco conceptual basado en la complementariedad de derechos establecidos en la Ley No. 300 Marco de la Madre Tierra y Desarrollo Integral para Vivir Bien (Bolivia 2012).

- Para la aplicación del enfoque metodológico de la gestión de los sistemas de vida de la Madre Tierra. En este marco el Estado Plurinacional de Bolivia está avanzando en la práctica de una propuesta alternativa al pago por servicios ecosistémicos (PSE) y a la Economía Verde para la construcción del horizonte civilizatorio del Vivir bien en armonía y equilibrio con la Madre Tierra.

- Por su parte los Sistemas de Vida de la Madre Tierra: a) es la interacción entre zonas de vida (ecosistemas) y las unidades socioculturales predominantes que las habitan y que han identificado los sistemas de manejo; b) desarrolla acuerdos de complementariedad con la Madre Tierra, donde el compromiso con los actores públicos, privados y comunitarios permite cumplir metas e indicadores conjuntos de mitigación y adaptación al cambio climático; c) la armonización de los sistemas de vida como acciones integrales busca reducir las brechas con relación a la construcción de sistemas productivos sustentables.

- El mecanismo conjunto se convierte en: a) un articulador de procesos adecuadas para las condiciones institucionales que garanticen del derecho propietario; b) uso de un enfoque de gestión territorial, c) Coordinación de metas comunes entre actores públicos y privados; d) desarrollo de intervenciones y acciones públicas articuladas; e) Articulación de bosques con agricultura; f) aplicación de esfuerzos sostenidos de transferencia de financiamiento y tecnologías

- Desarrollará un proceso de adscripción de las experiencias locales de manejo integral y sustentable del bosque al Mecanismo fortaleciéndolas en el marco de un enfoque de mitigación y adaptación al cambio climático.

- A través de un Fondo de Justicia Climática canaliza, administra y asigna de manera eficiente, transparente, expedita, oportuna y financieramente sostenible recursos públicos nuevos, predecibles, adicionales y sostenidos en el tiempo (siendo el Fondo Verde una fuente importante) para el apoyo a la realización de los planes, programas, proyectos, iniciativas, acciones y actividades conjuntas de mitigación y adaptación al cambio climático establecidas en el marco del "Mecanismo Conjunto de Mitigación y Adaptación para el Manejo Integral y Sustentable de los Bosques y la Madre Tierra”. Estos recursos financieros son transferidos para su ejecución directa a entidades públicas, gobiernos autónomos (departamentos y municipios), organizaciones comunitarias y actores privados de forma condicionada al cumplimiento concertado de objetivos y/o metas de mitigación y adaptación al cambio climático en el marco del manejo integral y 
sustentable de los bosques y Madre Tierra, promoviendo la implementación integrada de instrumentos de regulación, control, promoción, evaluación y monitoreo (Pacheco 2014).

\section{CONCLUSIONES}

El Calentamiento Global, los cambios climáticos y los eventos climáticos adversos, están generando fenómenos que influyen directamente en la forma de vida y los medios de vida de las poblaciones más vulnerables en todo el planeta. Son las comunidades indígenas, originarias y campesinas las que sienten los impactos de los eventos climáticos, porque los gobiernos no están desarrollando las medidas de forma oportuna y pertinente, con políticas de avance respaldadas por fomento a la ciencia, tecnológicas, gestión del conocimiento y fortalecimiento organizacional y equipamiento.

Ya llegando a las dos décadas de negociaciones para ver cómo desarrollar mecanismos de mitigación y adaptación para afrontar el cambio climático, los países siguen sin generar avances importantes en terreno, donde sean los productores locales y la población rural la que sienta los beneficios de las buenas políticas que puedan desarrollar.

Los trabajos desarrollados para ver los avances las legislaciones de los países muestran que son pocas las medidas normativas e institucionales que se desarrollando, no suficientes los recursos económicos que se están otorgando y el poco fomento que se están dando para encontrar soluciones prácticas para el desarrollo con conservación, medidas de mitigación y herramientas de adaptación. Pero también se denota un factor negativo en la implementación de las legislaciones que se van desarrollando, las que no están acompañadas por:

- Desarrollo de sistemas de monitoreo permanente y altamente confiable a los eventos climáticos extremos que se están suscitando.

- Mejora en las capacidades técnicas del personal, que además de ser insuficientes en cantidad, no cuentan con las herramientas necesarias.

- Escasos o irrelevantes recursos financieros que se están destinando a la implementación de medidas de mitigación y adaptación.

- Falta de tecnificación especializada para implementar medidas de corto, mediano y largo plazo y sustentables.

- Poco o ningún acompañamiento en las zonas o a los actores locales después que pasan los eventos climáticos para verificar el nivel de éxito de las medidas aplicadas y los esfuerzos desdoblados.

Analizando las normas aplicadas, no se denota con claridad cómo estas están contribuyendo a la conservación de la biodiversidad, mantenimiento, mejora y/o recuperación de los Recursos naturales, dado los bajos presupuestos que se asignan a estas carteras en los distintos gobiernos y países. Como se aplican las políticas, vemos que se atenta contra la seguridad alimentaria de las poblaciones amazónicas y alto andinas, quienes viven de los ecosistemas, de los productos que dan los suelos y la biodiversidad en su conjunto.

\section{REFERENCIAS}

Convención Marco de las Naciones Unidas sobre el Cambio Climático (CMNUCC), (2012). Status of Ratification of the Kyoto Protocol [URL: http://unfccc.int/kyoto_protocol/status_of_ratification/items/2613.php]. Visitado el 22 de enero de 2016.

Ministerio de Relaciones Exteriores, 2010. Declaración de la Conferencia Mundial de los Pueblos Sobre Cambio Climático y Defensa de la Vida Tiquipaya - Bolivia, (2010). http://www.cancilleria.gob.bo/sites/ default/files/ files/TIQUIPAYA/01\%20DECLARACION\%20DE\%20TIQUIPAYA\%2012 _10_2015\%20FINAL.pdf. Visitado el 20 Enero 2016. 
Fankhauser, S., Gennaioli, C. and Collins, M., (2014). Domestic dynamics and international influence: What explains the passage of climate change legislation? Documento de trabajo, Instituto Grantham de Investigación, Escuela de Economía y Ciencias Políticas de Londres.

Juan F. Silva y Susan S. Pinto (2015). Cambio Climático: Cronología de negociaciones. Sustentabilidad y desarrollo. http://sustentabilidadydesarrollo.com/2015/01/30/el-cambio- climatico-cronologia-de-negociaciones

Michal Nachmany, Sam Fankhauser, Terry Townshend, Jana Davidová, Nick Kingsmill, Tucker Landesman, Hitomi Roppongi, Philip Schleifer, Joana Setzer, Amelia Sharman, C. Stolle Singleton y Jayaraj Sundaresan. (2015). Estudio sobre legislación de cambio climático 2015: Informe sobre la legislación de cambio climático en 99 países. Resumen para responsables políticos. Londres-Inglaterra.

Pacheco Balanza, Diego. (2014). Una mirada a la política de bosques en Bolivia: Por la descolonización de las políticas - El mecanismo conjunto de mitigación y adaptación para el manejo integral y sustentable de los bosques y la Madre Tierra. Fundación de la Cordillera; Universidad de la Cordillera, La Paz-Bolivi

World Resources Institute, 2010, CAIT 2.0., (2010). Country GHG Emissions [URL: http://cait2.wri.org/]. Visitado el 7 de mayo de 2015. 